\title{
Hydrological changes during Meghalayan Stage from the Southern India
}

\author{
UPASANA S. BANERJI ${ }^{1 *}$, JITHU SHAJI ${ }^{1}$, MAYA K ${ }^{1}$, \\ CHANDANA K.R ${ }^{2}$, A. SHIVAM ${ }^{2}$, A.K. SUDHEER ${ }^{2}$, RAVI \\ BHUSHAN $^{2}$ AND D. PADMALAL ${ }^{1}$ \\ ${ }^{1}$ National Centre for Earth Science Studies, \\ Thiruvananthapuram-695011, Kerala, India \\ ${ }^{2}$ Physical Research Laboratory, Ahmedabad-380009, Gujarat, \\ India
}

Email: upasana.s.banerji@gmail.com*

The Indian Summer Monsoon (ISM) has been driven by the global atmospheric circulation and the climate. Southern India acts as a gateway for the ISM advancement over the Indian landmass and thus, the ISM variability is substantially recorded in the sedimentary archives of southern India. Here ISM variability during $3.5-5 \mathrm{ka}$ is reported from a lake sediment core raised from Kerala region, southern India chronologically supported by radiocarbon AMS dates. This study demonstrates dry climate as a result of weak ISM during 3.5-3.7 $\mathrm{ka}$ and 4.7-4.9 $\mathrm{ka}$ interrupted by ISM strengthening period. Both the period of dry climates (3.5-3.7 $\mathrm{ka}$ and 4.7-4.9) ka has been attributed to reduced Total Solar Irradiance (TSI). While the reduced TSI was accompanied by the increased El Nino events during 4.7-4.9 ka. These observations are in concurrence with declining temperature reported from SE Arabian Sea and Greenland Ice Core (GISP2) records. A vital role of TSI in controlling the ISM variability is envisaged with the possible occurrence of El Nino event restricting ISM during 4.7-4.9 ka, and thereby causing $4.2 \mathrm{ka}$ dry climate over the Indian subcontinent and other global records. This study highlights the behaviour of ISM with the possible role of natural forcing factor during 4.7-4.9 ka. 